\title{
Resistência mecânica à penetração de um argissolo amarelo distrófico típico sob diferentes sistemas de produção em plantio direto ${ }^{1}$
}

\author{
Soil mechanical resistance to penetration of a typic hapludalf under different production systems ${ }^{1}$
}

\author{
Claudia Fernanda Almeida Teixeira ${ }^{2}$ Eloy Antonio Pauletto ${ }^{3}$ João Baptista da Silva ${ }^{4}$
}

\section{- NOTA -}

RESUMO

Determinou-se a resistência mecânica à penetração (RP) de um Argissolo Amarelo Distrófico típico em 1997, em

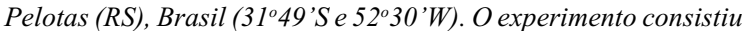
de oito tratamentos envolvendo diferentes culturas de cobertura, em rotação e sucessão no sistema plantio direto. As amostragens de $R P$ foram realizadas até a profundidade de 0,60 $\mathrm{m}$ e a umidade gravimétrica nas camadas de 0,00-0,10;0,10-0,20; 0,20-0,40 e $0,40-0,60 \mathrm{~m}$. Os sistemas de produção apresentaram valores de RP mais elevados até 0,20m; no tratamento azevém/feijão, aveia/soja, ervilhaca/milho o solo apresentou os maiores valores de RP.

Palavras-chave: compactação, manejo de solo, umidade de solo.

\section{ABSTRACT}

The determination of the penetration resistance $(R P)$ of a typical Hapludalf was accomplished in 1997, in Pelotas

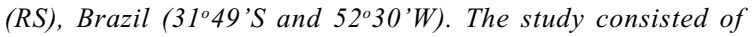
eight treatments with different cover crops, under rotation and succession under no-tillage. The samplings were accomplished up to the depth of $0.60 \mathrm{~m}$ and soil water content were accomplished in the layers of 0.00-0.10;0.10-0.20; $0.20-0.40$ and $0.40-0.60 \mathrm{~m}$. Starting from the obtained results it was concluded that the production systems presented values of RP more elevated until to $0.20 \mathrm{~m}$; the treatment rye-grass/ common bean, oat/soybean, vetch/corn presented the largest values of RP along the soil profile.

Key words: soil compaction, crop tillage systems, soil moisture.
A utilização de espécies com diferentes características de sistema radicular, que podem ser incluídas em sistemas de rotação e/ou de sucessão, é de extrema importância para o planejamento da recuperação de áreas fisicamente degradadas. Muitas vezes, a consorciação de duas ou mais espécies ou uma rotação adequada de culturas é capaz de melhorar as características físicas de solos degradados.

Pode-se, através de medidas de resistência do solo à penetração de raízes (RP), verificar o estado de compactação de um solo, utilizando-se para tanto, instrumentos denominados de penetrômetros. Desta forma, o objetivo do presente trabalho foi avaliar a resistência mecânica do solo à penetração em um Argissolo Amarelo Distrófico típico cultivado com diferentes sistemas de produção de grãos em plantio direto.

Utilizou-se um experimento conduzido em blocos ao acaso com três repetições, em que os tratamentos foram: $\mathrm{T}_{1}$ - Rotação de culturas: aveia/ soja, ervilhaca/milho, azevém/feijão; $T_{2}$ - Rotação de culturas: ervilhaca/milho, azevém/feijão, aveia/soja; $\mathrm{T}_{3}$ - Rotação de culturas: azevém/feijão, aveia/soja, ervilhaca/milho; $\mathrm{T}_{4}$ - Sucessão ervilhaca/milho; $\mathrm{T}_{5}-$

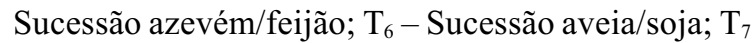
- Sucessão aveia + ervilhaca/soja; $\mathrm{T}_{8}$ - Sucessão aveia

\footnotetext{
${ }^{1}$ Parte da Dissertação de Mestrado apresentada pela primeira autora à Faculdade de Agronomia Eliseu Maciel (FAEM), UFPel. ${ }^{2}$ Engenheira Agrícola, Pós-graduando do Programa de Pós-graduação em Solos e Nutrição de Plantas, ESALQ/USP. Bolsista CAPES. Email:cfteixei@ig.com.br Autor para correspondência.

${ }^{3}$ Professor do Departamento de Solos, FAEM, Universidade Federal de Pelotas (UFPel), CP 354, 96001-970, Pelotas, RS. ${ }^{4}$ Professor do Instituto de Física e Matemática, UFPel.
} 
+ azevém/soja, considerando inverno/verão, nas safras agrícolas 1994/95, 1995/96 e 1996/97, respectivamente.

A RP foi determinada em novembro/1997, utilizando-se o penetrômetro de impacto em linha e em seis pontos distanciados de $1,20 \mathrm{~m}$, até a profundidade de $0,60 \mathrm{~m}$. Concomitantemente à determinação de RP foi avaliada a umidade de solo pelo método gravimétrico, em quatro pontos selecionados aleatoriamente ao longo da linha de amostragem de RP, nas camadas de 0,00-0,10; 0,100,$20 ; 0,20-0,40$ e $0,40-0,60 \mathrm{~m}$.

Dentre os tratamentos que envolveram rotação de culturas, $\mathrm{o} \mathrm{T}_{3}$ foi o que apresentou maiores valores de RP, em todas as camadas de solo estudadas (Tabela 1). Para CARANACHE (1990), estes valores causam restrições ao crescimento radicular das culturas, pois o mesmo considera que valores de RP acima de 2,5 MPa são considerados limitantes ao pleno crescimento das raízes das plantas.

Considerando a espécie envolvida, para MEDEIROS et al. (1987) a rotação de culturas com leguminosas e gramíneas constitui um sistema capaz de promover recuperação e conservação de solos fisicamente degradados. A rotação utilizada no tratamento $\mathrm{T}_{3}$, envolveu um sistema continuado de leguminosas de verão e só em 1996/97 houve a inclusão de milho ao sistema, o que poderia ter contribuído para uma diminuição dos valores de RP, em função de seu sistema radicular extenso e em constante renovação. Há de se considerar ainda a baixa umidade observada neste tratamento, por ocasião da determinação, causada provavelmente pela menor quantidade de resíduos vegetais deixados na superfície do solo, principalmente na safra agrícola 1996/97, que envolveu a ervilhaca como planta de cobertura, a qual além de apresentar menor massa vegetal do que as gramíneas azevém e aveia, apresenta maior taxa de decomposição.

Para o sistema de produção que envolveu sucessão de culturas, observa-se que os tratamentos $\mathrm{T}_{6}$ e $\mathrm{T}_{7}$ apresentaram valores de RP superiores aos demais. Este fato pode estar relacionado aos menores valores de umidade em profundidade (Tabela 1), devido provavelmente às menores contribuições dos resíduos vegetais deixados pelas plantas utilizadas como cobertura. O efeito benéfico da rotação de culturas e de plantas de cobertura sobre parâmetros físicos do solo é ressaltado por vários pesquisadores tais como DERPSCH (1991) e CATTELAN et al. (1997).

A partir da profundidade de $0,20 \mathrm{~m}$, observam-se menores valores de RP e maiores de umidade, em especial no tratamento $\mathrm{T}_{4}$. Apesar da utilização da ervilhaca como planta de cobertura e, por conseqüência, menor contribuição de resíduos vegetais na superfície do solo, esperava-se que a umidade do solo obtida fosse menor. Nesse tratamento, a inclusão de milho ao sistema de produção, pode ter sido o fator compensador, principalmente pelos efeitos positivos causados na estruturação do solo e, por conseguinte, nos valores de umidade do solo em função do sistema radicular mais denso e agressivo, característico dessa cultura.

Tabela 1 - Resistência mecânica do solo à penetração (RP, MPa) e umidade gravimétrica do solo $\left(\mathrm{U} \mathrm{kg} \mathrm{kg}^{-1}\right)$ para cada camada do perfil do solo, obtidos para os diferentes tratamentos em plantio direto

\begin{tabular}{|c|c|c|c|c|c|c|c|c|}
\hline \multirow{3}{*}{ Trat. $^{(2)}$} & \multicolumn{8}{|c|}{ Camada (m) } \\
\hline & \multicolumn{2}{|c|}{$0,00-0,10$} & \multicolumn{2}{|c|}{$0,10-0,20$} & \multicolumn{2}{|c|}{$0,20-0,40$} & \multicolumn{2}{|c|}{$0,40-0,60$} \\
\hline & $\mathrm{RP}$ & $\mathrm{U}$ & $\mathrm{RP}$ & $\mathrm{U}$ & $\mathrm{RP}$ & $\mathrm{U}$ & $\mathrm{RP}$ & $\mathrm{U}$ \\
\hline $\mathrm{T}_{1}$ & $2,48 b^{(1)}$ & $0,120 \mathrm{abc}$ & $2,29 \mathrm{~b}$ & $0,124 \mathrm{a}$ & $1,87 \mathrm{~cd}$ & $0,142 \mathrm{ab}$ & $2,27 \mathrm{a}$ & $0,152 \mathrm{~d}$ \\
\hline $\mathrm{T}_{2}$ & $2,92 \mathrm{ab}$ & $0,118 \mathrm{bc}$ & $2,42 \mathrm{~b}$ & $0,119 a b c$ & $1,84 \mathrm{~cd}$ & $0,149 \mathrm{a}$ & $2,05 \mathrm{a}$ & $0,225 \mathrm{a}$ \\
\hline $\mathrm{T}_{3}$ & $3,31 \mathrm{a}$ & $0,096 \mathrm{~d}$ & $3,34 \mathrm{a}$ & $0,107 \mathrm{bc}$ & $2,39 \mathrm{a}$ & $0,128 \mathrm{~b}$ & $2,30 \mathrm{a}$ & $0,168 \mathrm{~cd}$ \\
\hline $\mathrm{T}_{4}$ & $2,35 \mathrm{~b}$ & $0,133 \mathrm{a}$ & $2,26 \mathrm{~b}$ & $0,130 \mathrm{a}$ & $1,77 \mathrm{~d}$ & $0,150 \mathrm{a}$ & $1,99 \mathrm{a}$ & $0,210 \mathrm{ab}$ \\
\hline $\mathrm{T}_{5}$ & $2,29 \mathrm{~b}$ & $0,117 \mathrm{bc}$ & $2,51 \mathrm{ab}$ & $0,117 \mathrm{abc}$ & $2,16 a b c$ & $0,136 \mathrm{ab}$ & $2,17 \mathrm{a}$ & $0,163 \mathrm{~cd}$ \\
\hline $\mathrm{T}_{6}$ & $3,39 \mathrm{a}$ & $0,115 \mathrm{bc}$ & $2,82 \mathrm{ab}$ & $0,104 \mathrm{c}$ & $1,95 \mathrm{bcd}$ & $0,146 \mathrm{a}$ & $2,06 \mathrm{a}$ & $0,206 \mathrm{ab}$ \\
\hline $\mathrm{T}_{7}$ & $3,35 \mathrm{a}$ & $0,111 \mathrm{c}$ & $2,89 \mathrm{ab}$ & $0,108 \mathrm{bc}$ & $1,98 \mathrm{bcd}$ & $0,137 \mathrm{ab}$ & $2,36 \mathrm{a}$ & $0,206 a b$ \\
\hline $\mathrm{T}_{8}$ & $2,75 \mathrm{ab}$ & $0,129 \mathrm{ab}$ & $2,72 a b$ & $0,121 \mathrm{ab}$ & $2,28 \mathrm{ab}$ & $0,144 \mathrm{ab}$ & $2,26 \mathrm{a}$ & $0,192 \mathrm{bc}$ \\
\hline
\end{tabular}

(1) Médias não seguidas de mesma letra na coluna, dentro de cada variável, diferem entre si pelo teste de Duncan a 5\% de probabilidade de erro.

${ }^{(2)} \mathrm{T}_{1}$ - Rotação de culturas: aveia (inverno)/soja (verão), ervilhaca (inverno)/milho (verão), azevém (inverno)/feijão (verão); $\mathrm{T}_{2}-$ Rotação de culturas: ervilhaca (inverno)/milho (verão), azevém (inverno)/feijão (verão), aveia (inverno)/soja (verão); $\mathrm{T}_{3}$ - Rotação de culturas: azevém (inverno)/feijão (verão), aveia (inverno)/soja (verão), ervilhaca (inverno)/milho (verão); $\mathrm{T}_{4}$ - Sucessão ervilhaca (inverno)/milho

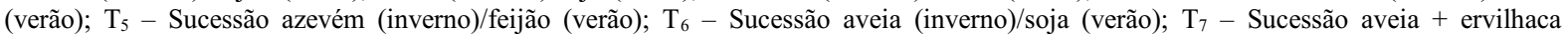
(inverno)/soja (verão); $\mathrm{T}_{8}$ - Sucessão aveia + azevém (inverno)/soja (verão). 


\section{REFERÊNCIAS BIBLIOGRÁFICAS}

CARANACHE, A. Penetr - a generalized semi-empirical model estimating soil resistance to penetration. Soil Tillage Research, Amsterdam, v.16, p.51-70, 1990.

CATtelan, A.J.; GAudênCiO, C.A.; SIlva, T.A. Sistemas de rotação de culturas em plantio direto e os microrganismos do solo, na cultura da soja, em Londrina.
Revista Brasileira de Ciência do Solo, Viçosa, v.21, p.293-301, 1997.

DERPSCH, R. et al. Controle da erosão no Paraná, Brasil: Sistemas de cobertura do solo, plantio direto e preparo conservacionista do solo. Londrina : GTZ-IAPAR, 1991. 272p.

MEDEIROS, J.C.; MIELNICZUK, J.; PEDÓ, F. Sistemas de culturas adaptadas a produtividade, recuperação e conservação do solo. Revista Brasileira de Ciência do Solo, Campinas, v.11, p.199-204, 1987. 